hơn và tình trang căng thẳng do nhiều yếu tố xung quanh tác động. Tại khoa cấp cứu bệnh viện Lão khoa Trung ương, nơi chúng tôi tiến hành nghiên cứu có được chia thành nhiều khu vực, nhiều khu phòng nhỏ, được giảm cường độ ánh sáng và hạn chế tiếng ồn vào buổi tối nên bệnh nhân cũng giảm nguy cơ bị rối loạn giấc ngủ nghiêm trong, tỉ lệ đảo ngược hoàn toàn chu kỳ thức ngủ thấp hơn so với các nghiên cứu khác.

\section{KẾT LUÂN}

Người bệnh sảng $\geq 60$ tuổi thường gặp là nhóm tuổi 80 - 89, tuổi trung bình mắc hội chứng sảng là $78,3 \pm 10,9$, nam giới gắp nhiều hơn nữ giới $(52,8$ và 47,2). Phần lớn sống cùng gia đình (68,9\%). Có 2 trường hợp sống trong nhà dưỡng lão chiếm tỉ lệ 1,9\%. Đa số người bệnh có biểu hiện suy giảm thị giác $(87,7 \%)$ và suy giảm thính giác $(81,1 \%)$. Triệu chứng gặp nhiều nhất là biểu hiện rối loạn định hướng không gian và giảm trí nhớ gần với tỉ lệ tương đương nhau là $89,6 \%$. Tiếp đó đến biểu hiện giảm khả năng duy trì sự chú ý $(61,3 \%)$. Ít gặp nhất là biểu hiện đảo ngược chu kì thức ngủ $(24,5 \%)$.

Khuyến nghị. Hội chứng sảng thường gặp ở người $\geq 60$ tuổi. Do đó, bác sĩ đa khoa và các bác sĩ chuyên khoa cần lưu ý để tránh bỏ sót.

Lời cảm ơn. Tôi xin chân thành cảm ơn những người bệnh và gia đình tham gia vào nghiên cứu, cảm ơn Khoa Cấp cứu bệnh viện Lão khoa Trung ương đã tạo điều kiện cho việc thực hiện nghiên cứu.

\section{TÀI LIÊU THAM KHẢO}

1. Kennedy M, Hwang $U$, Han JH. Delirium in the Emergency Department: Moving from tool-based research to system-wide change. J Am Geriatr Soc. 2020;68(5):956-958. doi:10.1111/jgs.16437

2. Wass S, Webster PJ, Nair BR. Delirium in the Elderly: A Review. Oman Med J. 2008;23(3):150-157.

3. Fong TG, Tulebaev SR, Inouye SK. Delirium in elderly adults: diagnosis, prevention and treatment. Nat Rev Neurol. 2009;5(4):210-220. doi:10.1038/nrneurol.2009.24

4. Carpenter CR, Bassett ER, Fischer GM, Shirshekan J, Galvin JE, Morris JC. Four sensitive screening tools to detect cognitive dysfunction in geriatric emergency department patients: brief Alzheimer's Screen, Short Blessed Test, Ottawa 3DY, and the caregiver-completed AD8. Acad Emerg Med Off J Soc Acad Emerg Med. 2011;18(4):374-384. 2712.2011.01040.x

5. Han JH, Vasilevskis EE, Chandrasekhar R, et al. Delirium in the Emergency Department and Its Extension into Hospitalization (DELINEATE) Study: Effect on 6-month Function and Cognition. J Am Geriatr Soc. 2017;65(6):1333-1338. doi:10.1111/jgs.14824

6. Pisani MA, Murphy TE, Van Ness PH, Araujo KLB, Inouye SK. Characteristics associated with delirium in older patients in a medical intensive care unit. Arch Intern Med. 2007:167(15):16291634. doi:10.1001/archinte.167.15.1629

7. Trzepacz PT, Franco JG, Meagher DJ, et al. Delirium Phenotype by Age and Sex in a Pooled Data Set of Adult Patients. J Neuropsychiatry Clin Neurosci. 2018;30(4):294-301. doi:10.1176/appi.neuropsych.18020024

8. Martins $\mathbf{S}$, Fernandes $\mathbf{L}$. Delirium in elderly people: a review. Front Neurol. 2012;3:101. doi:10.3389/fneur.2012.00101

\title{
NGHIÊN CỨU TỔNG QUAN HÊ THỐNG VỀ ĐÁNH GIÁ KĨ NĂNG THỰC HÀNH NGHỀ NGHIỆP CỦA NHÂN VIÊN BÁN HÀNG TẠI CÁC NHÀ THUỐC TƯ NHÂN
}

\section{TÓM TẮT}

Dược sĩ cộng đồng (DSCĐ) là nhân tố quan trong trong vân hành hệ thống y tế đảm bảo sức khỏe cộng đồng nển cần đảm bảo kiến thức chuyên môn và trau dồi kỹ năng thực hành nghề nghiêp (KNTHNN). Tổng quan hệ thống các kết quả đánh giá kỹ năng thực

*Đai hoc Y Dươ TP.HCM

Chịu trách nhiệm chính: Nguyễn Thị Thu Thủy

Email: nguyenthuthuy@ump.edu.vn

Ngày nhận bài: 15.9.2021

Ngày phản biên khoa hoc: 12.11.2021

Ngày duyệt bài: 22.11.2021

\section{Võ Thảo Nguyên*, Nguyễn Thị Thu Thủy*}

hành nghề nhiệp của nhân viên bán hàng tại các nhà thuốc tư nhân trên thế giới là cần thiết nhằm cung cấp bức tranh toàn cảnh về đặc điểm, kỹ năng hành nghề cũng như các yếu tố liên quan đến KNTHNN của dược sĩ cộng đồng. Phân tích tổng quan hệ thống được thực hiện theo tiêu chuẩn PRISMA trên cơ sở dữ liểu Pubmed, Cochrane và Research Gate bằng câu lệnh, từ khóa và tiêu chí lựa chọn, loại trừ phù hợp. Dữ liệu về đăc điểm các nghiên cứu và đánh giá KNTHNN của DSCĐ được trích xuất và tổng hợp. Trong 6 nghiên cứu được chon, có 4 nghiên cứu sử dung phương pháp mồ phỏng đóng vai người mua, 2 nghiên cứu khảo sát tư đánh giá và quan sát bí mât. Kỹ năng hỏi thu thập thông tin từ người bệnh có tỉ lệ chênh lệch 
cao 1,7\% - 73,3\% giữa các quốc gia. Kỹ năng tư vấn cung cấp thông tin của DSCĐ ở Việt Nam có kết quả thấp nhất với chỉ $10 \%$ và không một DSCĐ nào khuyên khách hàng đến chuyên gia sức khỏe, trong khi đó kỹ năng này ở các quốc gia châu Âu và Úc là khá cao. Kỹ năng tư vấn của DSCĐ rất cao ở Đức và yếu kém ở Việt Nam và Jordan. Kết quả này giúp định hướng những nhận định phù hợp hơn trong công tác giáo dục đào tạo cũng như quản lý dược sĩ cộng đồng tại Việt Nam.

Tử khóa: dược sĩ cộng đồng, đánh giá, tư vấn, kỹ năng nghề nghiệp, nhà thuốc.

\section{SUMMARY}

SYSTEMATIC REVIEW OF THE EVALUATION OF PRACTICE SKILLS OF COMMUNITY PHARMACIST AT COMMUNITY PHARMACY

Community pharmacists (CP) are an important factor in the operation of health system to ensure public health, so it is necessary to ensure professional knowledge and cultivate professional practice skills (PPS). A systematic review of PPS assessment of community pharmacist (CP) at public pharmacies around the world is neccessary to provide a complete picture of the characteristics, PPS as well as the factors related to PPS of community pharmacists. Systematic review was performed according to PRISMA standards on Pubmed, Cochrane and Research Gate databases using appropriate statements, keywords and inclusion and exclusion criteria. Data on characteristics of studies and PPS of $\mathrm{CP}$ were extracted and aggregated. In the 6 selected studies, there are 4 studies using play-role method of buyer, 2 self-assessment survey studies and covert observations. The questioning skill and collecting information from patients has a high rate ranging from $1,7 \%$ to $73,3 \%$ between countries. The counseling skill - providing information in Vietnam has the lowest level with only $10 \%$ and not a single CP consulting patients visiting a health professional, while this skill is found in European countries and Australia with high level. The consulting skills of CP are very high in Germany and weak in Vietnam and Jordan. This result helps to guide more appropriate judgments in education and training as well as community pharmacist management in Vietnam.

Keywords: community pharmacists, evaluation, counselling, professional practice skills, community pharmacies.

\section{I. ĐẶT VẤN ĐỀ}

Vai trò của dược sĩ cộng đồng đã được Tổ chức Y tế Thế giới (WHO - World Health Organization) xác định và thể hiện qua công tác tư vấn cho người bệnh, thông tin thuốc cho các nhân viên y tế cùng cộng đồng nói chung và tham gia các chương trình tăng cường sức khỏe [11]. Trong một báo cáo của WHO, tỉ lệ nhân lực y tế ngành dược với mật độ dược sĩ đại học phục vụ y tế năm 2018 là $0,21 / 1.000$ dân [3]. Để thực hiện tốt vai trò của mình, dược sĩ cộng đồng
(DSCĐ) cần đảm bảo kiến thức chuyên môn và luôn trau dồi những kỹ năng thực hành nghề nghiệp (KNTHNN) cần thiết phục vụ cho nhiệm vụ cung ứng thuốc đạt chất lượng, hiệu quả, an toàn và hợp lý. KNTHNN của DSCĐ hay nhân viên bán hàng (NVBH) tại nhà thuốc liên quan trực tiếp đến sức khỏe cộng đồng là một vấn đề rất đáng quan tâm. Để có được những thông tin tổng hợp về KNTHNN của NVBH và các DSCĐ trên thể giới, nghiên cứu tổng quan hệ thống các kết quả đánh giá KNTHNN của NVBH tại các nhà thuốc cộng đồng được thực hiện.

\section{II. ĐỐI TƯỢNG VÀ PHƯƠNG PHÁP NGHIÊN CỨU}

Đối tượng nghiên cứu. Dữ liệu y văn về KNTHNN của DSCĐ trên thế giới

Câu hỏi nghiên cứu. Câu hỏi nghiên cứu: "Kỹ năng thực hành nghề nghiệp của nhân viên bán hàng tại các nhà thuốc tư nhân trên thế giới hiện nay như thế nào?". Câu hỏi nghiên cứu được thiết lập theo PICO (bảng 1).

\section{Bảng 1. Tư khóa cho phương pháp PICO}

\begin{tabular}{|c|c|c|}
\hline $\mathbf{P}$ & $\begin{array}{c}\text { Population (Bệnh } \\
\text { nhân hoắc Quần } \\
\text { thể) }\end{array}$ & $\begin{array}{c}\text { Dược sĩ cộng đồng / } \\
\text { Nhẩn viên bán hàng } \\
\text { đang làm viếc tại các } \\
\text { nhà thuốc tư nhân }\end{array}$ \\
\hline $\mathbf{I}$ & $\begin{array}{c}\text { Intervention (Can } \\
\text { thiệp, điều trị) }\end{array}$ & không sử dụng \\
\hline $\mathbf{C}$ & $\begin{array}{c}\text { Comparison } \\
\text { (Nhóm chứng) }\end{array}$ & không sử dụng \\
\hline $\mathbf{O}$ & $\begin{array}{c}\text { Outcome (Kết } \\
\text { quả) }\end{array}$ & $\begin{array}{c}\text { Kỹ năng thực hành } \\
\text { nghề nghiệp }\end{array}$ \\
\hline
\end{tabular}

Phương pháp nghiên cứu. Nghiên cứu tổng quan hệ thống theo tiêu chuẩn PRISMA bao gồm tìm kiếm, sàng lọc, trích xuất và tổng hợp kết quả các nghiên cứu về đánh giá kỹ năng thực hành nghề nghiệp của NVBH tại các nhà thuốc tư nhân. Các bước nghiên cứu được thực hiện độc lập bởi 2 nghiên cứu viên, với những nội dung khác biệt, 2 nghiên cứu viên sẽ cùng thảo luận để có sự đồng thuận chung. Nếu không đạt đến đồng thuận, sự can thiệp của nghiên cứu viên thứ 3 được thực hiện cho đến khi có sự đồng thuận.

Tìm kiếm. Trên cơ sở dữ liệu Pubmed, Cochrane Library và Research Gate đến tháng 05/2021 với các từ khóa: community pharmacistprofessional, practice skills, counselling, community pharmacy services và câu lệnh: AND, OR kết hợp tính năng MeSH Terms.

Sàng lọc và lựa chọn. Các nghiên cứu được tìm thây trên cơ sở dữ liệu được sàng lọc dựa trên tiêu đề và bản tóm tắt theo tiêu chí lựa chọn và loại trừ như sau: 
Tiêu chí lứa chon: - Đối tượng tham gia gồm những dược sĩ cộng đồng hoặc nhân viên bán hàng đang làm việc tại các nhà thuốc tư nhân/nhà thuốc cộng đồng.

- Nghiên cứu đánh giá kỹ năng thực hành nghề nghiệp của người bán hàng tại cơ sở bán lẻ thuốc

\section{Tiêu chí loai trừ}

- Nghiên cứu không có toàn văn

- Địa điểm nghiên cứu là các nhà thuốc tư nhân /nhà thuốc cộng đồng.

- Nghiên cứu không được công bố bằng ngôn ngữ Tiếng Anh và Tiếng Việt.

- Nghiên cứu có đối tượng nghiên cứu là người bệnh hoặc sinh viên dược đang học tập nghiên cứu.

- Phương pháp nghiên cứu khảo sát qua email hoăc phỏng vấn thông qua điện thoại.

- Nghiên cứu can thiệp bằng những thuốc xác định hoăc các tên bệnh cụ thể.

- Nhà thuốc thuộ̣c bệnh viện, các chuỗi nhà thuốc hay nhà thuốc nằm trong các siêu thị. khu vực

- Nhà thuốc có liên kết với bệnh viện trong

- Các loại hình nhà thuốc có liên kết với các tổ chức quổc tế thực hiện chương trình can thiệp cải thiện năng lực dược sĩ cộng đồng.

- Nghiên cứu liên quan đến chi phí hay sự cải thiện kết quả tiêu dùng của người bệnh hoặc tình trạng kinh tế của các nhà thuốc

\section{Trích xuất và tổng hợp dữ liêu}

Các nghiên cứu được chon lọc sẽ được trích xuất các dữ liệu về đặc điểm nghiên cứu như: tác giả, quốc gia, năm, phương pháp nghiên cứu, tình huống được sử dụng và các kỹ năng đánh giá NVBH.

\section{KẾT QUẢ NGHIÊN CỨU}

Tìm kiếm và lựa chọn nghiên cứu. Kết quả tìm kiếm ban đầu với 556 tài liệu từ Pubmed/Medline, 527 tài liệu từ Cochrane Library 53 tài liệu từ Research Gate. Trong đó, 865 nghiên cứu bị loại trừ do trùng lặp dựa trên mã số tài liệu, 271 nghiên cứu đã được sàng lọc tiêu đề/tóm tắt với 43 nghiên cứu còn lại sau sàng lọc. Theo đó, 37 nghiên cứu loại (35 nghiên cứu không thỏa tiêu chí lựa chọn và 2 nghiên cứu không có toàn văn), 6 nghiên cứu cuối cùng đủ điều kiện để thực hiện các bước tổng quan hệ thống tiếp theo (Hình 1).

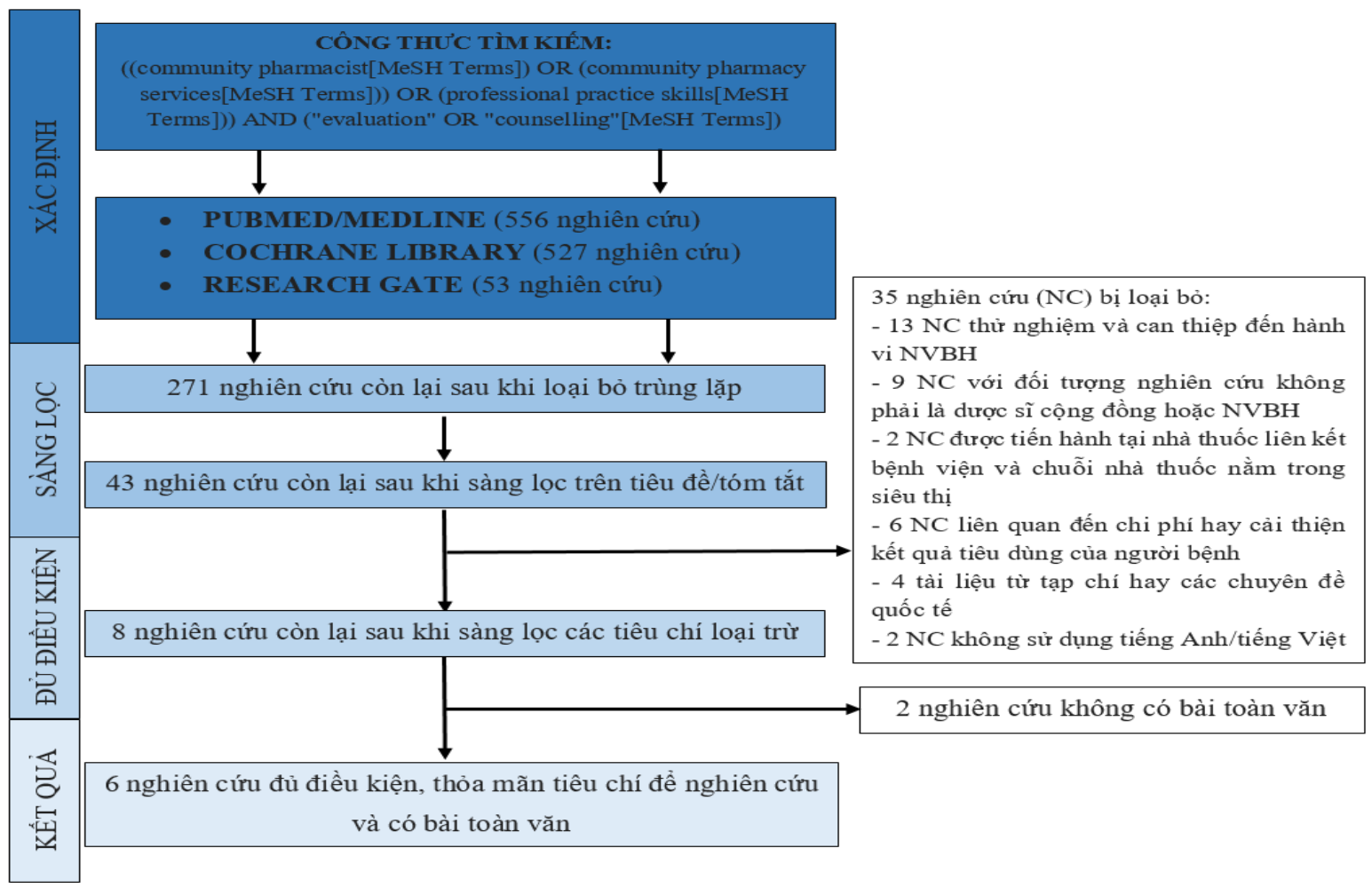

Hình 1. Quy trinh tìm kiếm và lựa chọn nghiên cứu đưa vào phân tích tổng quan Đặc điểm các nghiên cứu liên quan đển kỹ năng thực hành nghề nhiệp của nhân viên bán hang. Đặc điểm chính của 6 nghiên cứu lựa chọn được thể hiện chi tiết trong Bảng 2. 
Bảng 2. Đặc điểm chính của các nghiên cứu kỹ năng thực hành nghề nghiệp của nhân viên bán hàng

\begin{tabular}{|c|c|c|c|c|c|}
\hline $\begin{array}{c}\text { Tác giả } \\
\text { chính (năm) }\end{array}$ & Quốc gia & $\begin{array}{c}\text { Đối tượng } \\
\text { nghiền } \\
\text { cứu (NC) }\end{array}$ & $\begin{array}{l}\text { Phương } \\
\text { pháp NC }\end{array}$ & Tình huống & $\begin{array}{c}\text { Các kỹ năng đánh } \\
\text { giá }\end{array}$ \\
\hline $\begin{array}{c}\text { Zimenkovsky } \\
\text { A. (2017) } \\
{[13]}\end{array}$ & $\begin{array}{l}\text { Lviv, } \\
\text { Ukraine }\end{array}$ & $\begin{array}{c}150 \mathrm{NVBH} \\
\text { tại } 139 \text { nhà } \\
\text { thuốc }\end{array}$ & $\begin{array}{l}\text { Đóng vai } \\
\text { người mua } \\
\text { thuốc }\end{array}$ & Em bé 2 tuổi bị ho khan & $\begin{array}{c}\text { Kỹ năng hỏi: về tình } \\
\text { tranng sức khỏe của } \\
\text { người bệhh và kỹ } \\
\text { năng tư vấn loại } \\
\text { thuốc sứ dung }\end{array}$ \\
\hline $\begin{array}{l}\text { Collins J. C. } \\
(2017)[4]\end{array}$ & Sydney, Úc & $\begin{array}{l}158 \text { NVBH } \\
\text { tại } 11 \text { nhà } \\
\text { thuốc tư } \\
\text { nhân }\end{array}$ & $\begin{array}{l}\text { Đóng vai } \\
\text { người mua } \\
\text { thuốc }\end{array}$ & $\begin{array}{c}3 \text { tình huống KH yêu câu } \\
\text { mua } 1 \text { tên thuốc không } \\
\text { kê đơn xác định: } \\
\text {-Gastrostop (loperamide) } \\
\text { cho người mua bị tiêu chảy } \\
\text {-Somac (pantoprazole) } \\
\text { cho } 1 \text { phụ nữ > } 50 \text { tuổi bị } \\
\text { ợ nóng } \\
\text {-Ventolin (salbutamol) } \\
\text { cho người mua bị hen suyến }\end{array}$ & $\begin{array}{l}\text { Kỹ năng đưa ra lời } \\
\text { khuyên dẫn đến giới } \\
\text { thiệu người bệnh } \\
\text { đến bác sĩ }\end{array}$ \\
\hline $\begin{array}{c}\text { Schumacher } \\
\text { P. M. (2019) } \\
\text { [9] }\end{array}$ & Đức & $\begin{array}{l}520 \text { nhân } \\
\text { viên của } \\
119 \text { nhà } \\
\text { thuốc }\end{array}$ & $\begin{array}{l}\text { NC mô tả sử } \\
\text { dụng bảng } \\
\text { câu hỏi tự trả } \\
\text { lời cho nhân } \\
\text { viên dược }\end{array}$ & $\begin{array}{c}\text { Không có tình huống cụ } \\
\text { thể }\end{array}$ & $\begin{array}{l}\text { Kỹ năng tư vấn và } \\
\text { cunng cấp thông tin } \\
\text { vế dạng dùng và } \\
\text { cách dùng thuốc. }\end{array}$ \\
\hline $\begin{array}{c}\text { Seiberth J. M. } \\
\text { (2020) [10] }\end{array}$ & Đức & $\begin{array}{c}\text { Phần }(\mathrm{A}) \mathrm{N} \\
=1068 \\
\mathrm{NVBH} \\
\text { Phần }(\mathrm{B}) \mathrm{N} \\
=25 \mathrm{NVBH} \\
\text { trong } 5 \text { nhà } \\
\text { thuốc }\end{array}$ & $\begin{array}{c}\text { NC gồm } 2 \\
\text { phần được } \\
\text { thực hiện } \\
\text { bao gồm }(A) \\
\text { tự báo cáo } \\
\text { và (B) quan } \\
\text { sát không } \\
\text { tham gia }\end{array}$ & $\begin{array}{c}\text { Không có tình huống cụ } \\
\text { thể }\end{array}$ & \begin{tabular}{|l} 
Kỹ năng hỏi thu thập \\
thông tin trong quá \\
trình tham vấn tự' \\
dùng thuốc: thông \\
tin người bệnh về \\
'tình trang sức khỏe \\
hiện thời' và 'thuốc \\
người bênh đang sử \\
dụng đồng thời'. \\
\end{tabular} \\
\hline $\begin{array}{l}\text { Hammad E. } \\
\text { A. (2018) [7] }\end{array}$ & $\begin{array}{l}3 \text { thành phố } \\
\text { ơ Jordan: } \\
\text { Amman, } \\
\text { Zarqa, Al- } \\
\text { Salt }\end{array}$ & $\begin{array}{l}38 \text { NVBH taii } \\
38 \text { nhà } \\
\text { thuốc (trong } \\
\text { đó có } 29 \\
\text { nhà thuốc } \\
\text { tư') }\end{array}$ & $\begin{array}{l}\text { Nghiên cứu } \\
\text { cắt ngang } \\
\text { mô phỏng } \\
\text { đóng vai } \\
\text { người mua } \\
\text { hàng và yêu } \\
\text { cầu nhận } \\
\text { được tư vấn }\end{array}$ & $\begin{array}{c}\text { Mua thuốc điều trị đau } \\
\text { đầu }\end{array}$ & $\begin{array}{c}\text { Kỹ năng thu thập } \\
\text { thông tin cần thiết } \\
\text { về các triệu chứng } \\
\text { hoặc bênh sứ của } \\
\text { người bệnh và kỹ } \\
\text { năng tư vấn vê } \\
\text { thuốc }\end{array}$ \\
\hline $\begin{array}{c}\text { Trần Minh } \\
\text { Luân (2017) } \\
\text { [2] }\end{array}$ & $\begin{array}{l}\text { Đồng Tháp, } \\
\text { Việt Nam }\end{array}$ & $\begin{array}{c}60 \text { người } \\
\text { bán lẻ thuốc } \\
\text { taii } 60 \text { nhà } \\
\text { thuốc đạt } \\
\text { chuẩn GPP }\end{array}$ & $\begin{array}{l}\text { NC quan sát } \\
\text { trực tiếp } \\
\text { thông qua } \\
\text { đóng vai } \\
\text { người mua } \\
\text { thuốc }\end{array}$ & $\begin{array}{l}\text { Mua thuốc kê đơn } \\
\text { prednisolon 5mg cho } \\
\text { bệnh viêm khớp gối }\end{array}$ & $\begin{array}{c}\text { Kỹ năng khai thác } \\
\text { thông tin, kỹ năng } \\
\text { tư vấn và ra lẻ } \\
\text { thuốc. }\end{array}$ \\
\hline $\begin{array}{l}\text { Theo bảng } \\
\text { ơ rải rác } 3 \text { ch } \\
\text { cứu ở Ukrain } \\
\text { cứu ở Úc, } 1 \text { ns } \\
\text { Việt Nam. Tro } \\
\text { sử dụng phươ }\end{array}$ & $\begin{array}{l}\text { 1, các ngh } \\
\text { âu lục trên } \\
\text { e, } 2 \text { nghiên } \\
\text { ghiên cứu ở } \\
\text { ong đó có } \\
\text { ng pháp mó }\end{array}$ & $\begin{array}{l}\text { cứu được } \\
\text { giới gốm } \\
\text { u ở Đức, } \\
\text { dan, } 1 \text { ngl } \\
\text { hiên cứu }\end{array}$ & $\begin{array}{ll}\text { n hành } & \mathrm{m} \\
\text { nghiên } & \mathrm{du} \\
\text { nghiên } & \mathrm{ki} \\
\text { cứu ở } & \mathrm{ph} \\
\text {,67\%) } & \text { sá } \\
\text { i người } & \text { th }\end{array}$ & \multicolumn{2}{|c|}{$\begin{array}{l}\text { mua }[4],[7],[2] ; 1 \text { nghiên cứu }(16,67 \%) \text { sủ } \\
\text { dưng phương pháp khảo sát với bảng câu hỏi tụ } \\
\text { kiểm cho NVBH[9]; } 1 \text { nghiên cứu còn lại vớ } \\
\text { phương pháp thu thâp thông tin thông qua quan } \\
\text { sát bí mật dưới sự đồng ý chấp thuận của ngườ } \\
\text { tham gia [10]. }\end{array}$} \\
\hline
\end{tabular}


Tình huống được sử dụng trong 4 nghiên cứu với phương pháp mô phỏng đóng vai người mua rất đa dạng. Nghiên cứu tại Lviv, Ukraine với kịch bản em bé 2 tuổi bị ho khan 3 tuần đã sử dụng siro Althaea nhưng vẫn còn ho, qua đó NVBH sẽ thể hiện kỹ năng hỏi và tư vấn cho khách hàng. Nghiên cứu ở Sydney, Úc với 3 tình huống yêu cầu mua thuốc không kê đơn cụ thể gồm Gastrostop cho người mua bị tiêu chảy đi 2-3 lần/ngày, đầy hơi, đã sử dụng thuốc này trước đó; Somac cho 1 phụ nữ trền 50 tuổi bị ợ nóng sau khi ăn mỗi ngày, đau lưng và đau cánh tay, đã sử dụng thuốc Mylanta và Voltaren; Ventolin cho người mua bị hen suyễn từ nhỏ, khò khè, đã sử dụng Ventolin 3-4 lần/ngày nhưng chưa từng trao đổi với bác sĩ. 3 tình huống này nhằm thể hiện kỹ năng tư vấn khuyên người bệnh đến gặp bác sĩ của NVBH [4]. Nghiên cứu tại 3 thành phố ở Jordan với tình huống mua thuốc và tìm kiếm lời khuyên cho triệu chứng đau đâu vì người dân Jordan được ước tính rằng đến $82 \%$ bị đau đâu ít nhất 1 lần 1 năm [7]. Nghiên cứu còn lại ở Việt Nam sử dụng kịch bản mua thuốc kê đợn prednisolon $5 \mathrm{mg}$ cho người bệnh viêm khớp gối nhằm quan sát các kỹ năng khai thác thông tin, kỹ năng tư vấn và ra lẻ thuốc của NVBH [2].

Các kết quả chính trong các nghiên cứu liên quan đến kỹ năng thực hành nghề nhiêp của nhân viên bán hàng

Chi tiết về từng kỹ năng thực hành nghề nghiêp của NVBH được đánh giá trong các nghiển cứu thể hiện trong Bảng 3.

Bảng 3. Các kỹ năng thực hành nghề nghiệp của nhân viên bán hàng hay dược sĩ cộng đồng được đánh giá trong nghiên cứu

\begin{tabular}{|c|c|c|c|c|c|c|c|}
\hline \multicolumn{2}{|c|}{$\begin{array}{l}\text { Kỹ năng } \\
\text { được đánh giá }\end{array}$} & $\left\{\begin{array}{c}\text { Zimenko } \\
\text { sky A. } \\
(2017)\end{array}\right.$ & $\begin{array}{c}\text { Collins J. } \\
\text { C. } \\
(2017)\end{array}$ & $\begin{array}{l}\text { Schumache } \\
\text { r P. M. } \\
\text { (2019) }\end{array}$ & $\begin{array}{l}\text { Seiberth J. } \\
\text { M. (2020) }\end{array}$ & $\begin{array}{l}\text { Hammad E } \\
\text { A. (2018) }\end{array}$ & $\begin{array}{c}\text { Trân Minh } \\
\text { Luân } \\
\text { (2017) }\end{array}$ \\
\hline \multicolumn{2}{|c|}{ Cơ sở tiêu chí đánh giá } & $\begin{array}{l}\text { Hê̂ thống } \\
\text { phân loại }\end{array}$ & $\begin{array}{c}\text { Quy trình } \\
\text { bán thuốc } \\
\text { WHAT - }\end{array}$ & $\begin{array}{c}\text { Các chuyên } \\
\text { gia trong }\end{array}$ & \begin{tabular}{|} 
Hướng dân \\
quốc gia về \\
tư vấn tự \\
dùng thuốc
\end{tabular} & $\begin{array}{l}\text { Công thức } \\
\text { WWHAM }\end{array}$ & $\begin{array}{l}\text { Nguyên tắc } \\
\text { GPP về } \\
\text { "Thực hành }\end{array}$ \\
\hline \multirow{3}{*}{$\begin{array}{l}\text { Kỹ } \\
\text { năng } \\
\text { hỏi }\end{array}$} & \multirow{3}{*}{\begin{tabular}{|l|} 
bệnh \\
Về triệu chứng bệnh \\
Về tiền sứ sư dưng \\
thuốc/dị ứng thuốc \\
\end{tabular}} & $73,3 \%$ & \multirow{3}{*}{$63 \%$} & \multirow{3}{*}{ - } & $63 \%$ & $18,4 \%$ & $1,7 \%$ \\
\hline & & $0,7 \%$ & & & $43 \%$ & $23,7 \%$ & $5 \%$ \\
\hline & & $18,7 \%$ & & & $37 \%$ & - & $1,7 \%$ \\
\hline \multirow{3}{*}{\begin{tabular}{|c|} 
Kỹ \\
năng tu \\
vấn - \\
cung \\
cấp \\
thông \\
tin \\
\end{tabular}} & $\begin{array}{l}\text { Phương pháp tiếp } \\
\text { cận không dùng } \\
\text { thuốc/lối sống }\end{array}$ & $2 \%$ & - & - & - & $0 \%$ & $0 \%$ \\
\hline & $\begin{array}{l}\text { Sữ dụng thuốc đúng } \\
\text { cách }\end{array}$ & $99,3 \%$ & - & $87,7 \%$ & $33 \%$ & $36,8 \%$ & $10 \%$ \\
\hline & $\begin{array}{c}\text { Lựa chọn loại } \\
\text { thuốc/dạng dùng }\end{array}$ & $34,7 \%$ & - & $23,5 \%$ & - & $2,6 \%$ & - \\
\hline \multicolumn{2}{|c|}{$\begin{array}{c}\text { Kỹ năng đưa ra lời khuyên } \\
\text { đến gặp bác sĩ }\end{array}$} & - & $66 \%$ & - & $12 \%$ & - & $0 \%$ \\
\hline
\end{tabular}

Chú thích: (-) Không được đề cập hoặc không được đánh giá trong nghiên cứu

- PCNE (Pharmaceutical Care Network Europe) - Mạng lưới chăm sóc dược phẩm châu Âu

- BAK (Federal Chamber of Pharmacists) Phòng dược sĩ liên bang

- WWHAM (Who - What - How long - Action - Medication) - Ai, triệu chứng gì, bao lâu, hành động và thuốc đã dùng

Theo bảng 3, các nghiên cứu đã sử dụng đa dạng cơ sở để đặt ra tiêu chí đánh giá kỹ năng cho NVBH phù hợp với quy định hành nghề ở mỗi quốc gia như ở Ukraine nghiên cứu sử dụng hê thống PCNE (Pharmaceutical Care Network Europe) - Phân loại cho các vấn đề liên quan đến thuốc của mạng lưới chăm sóc dược phẩm châu Âu để thiết kế bộ câu hỏi khảo sát [5]. Ở Úc, nghiên cứu sử dụng bảng thu thập dữ liệu gồm 18 câu hỏi theo quy trình "WHAT - STOP GO" do Hiệp hội Dược phẩm Úc hướng dẫn cho DSCĐ [8]. Nghiên cứu ở Jordan dựa trên các tiêu chí tư vấn theo công thức WWHAM gồm các câu hỏi theo thứ tự: người bệnh là ai (Who), các triệu chứng là gì (What), xuất hiện các triệu 
chứng bao lâu (How long), hành động đã thực hiện (Action) và các thuốc đã dùng (Medication) [7]. Ớ Đức, nghiên cứu của Schumacher P. M. (2019) với bảng khảo được xây dựng có hệ thống do một nhóm chuyên gia gồm các dược sĩ nghiên cứu nhiều kinh nghiệm [9]. Nghiên cứu của Seiberth J. M. (2020) dựa trên hướng dẫn quốc gia về tư vấn tự dùng thuốc do BAK xuất bản để thu thập thống tin [6]. Ở Việt Nam, nghiên cứu dựa trên bộ nguyên tắc tiêu chuẩn GPP [1], [2].

ớ các nghiên cứu cho thấy kỹ năng hỏi thu thập thông tin của NVBH khác nhau tùy nhóm câu hỏi như khai thác về thông tin người bệnh có tỉ lệ hỏi chênh lệch cao 1,7\% - 73,3\%. Khai thác liên quan đến triệu chứng bệnh có tỷ lệ dao động từ $0,7 \%$ (Ucraine) đến $5 \%$ ở Việt Nam và cao nhất là $43 \%$ ở Đức [2], [10]. Khai thác liên quan đến tiền sử sử dụng thuốc hay dị ứng thuốc của người bênh chiếm 1,7\% ở Việt Nam [2]. Nghiên cứu ở Úc cũng cho một kết quả tổng quan về kỹ năng đặt câu hỏi cao nhất $63 \%$ khi NVBH thực hiện một lượt giao dịch với khách hàng [4].

Về kỹ năng tư vấn - cung cấp thông tin của NVBH cho người mua, kỹ năng tư vấn về dạng dùng của thuốc có sự chênh lệch lớn với $34,7 \%$ ở Ukraine, $23,5 \%$ ở Đức và 2,6\% tại Jordan [7]. Kỹ năng NVBH tư vấn về lối sống hay phương pháp chữa trị không dùng thuốc thể hiện rất thấp ở 3 quốc gia có đánh giá về tiêu chí này là Việt Nam $(0 \%)$, Jordan $(0 \%)$ và Ukraine $(2 \%)$ [2], [7]. Kết quả của kỹ năng tư vấn về việc sử dụng thuốc đúng cách cho thây mức độ cao hơn các khía canh tư vấn khác cùng nhóm với tỉ lệ cao nhất là $99,3 \%$ và $87,7 \%$ ở Ukraine, thấp nhất vẫn là nhóm NVBH ở Việt Nam với chỉ $10 \%$ thực hiện [2], [9].

Phần kỹ năng đưa ra lời khuyên để người bệnh đến gặp bác sĩ cũng có tỉ lệ chênh lệch cao giữa nghiên cứu ở Úc và Đức $(66 \%$ và $12 \%$; tương ứng) [4], [10]. Trong khi đó, không một NVBH nào ở Việt Nam khuyên khách hàng đển chuyên gia sức khỏe [2].

\section{BÀN LUẬN}

Những nghiên cứu đưa vào phân tích được tiến hành ở các quốc gia thuộc 3 châu lục khác nhau. Ngoài 2 quốc gia là Đức và Úc, 3 quốc gia còn lại đều là những quốc gia đang phát triển về kinh tế gồm Ukraine, Jordan và Việt Nam. Khác nhau từ nền kinh tế, quy định hành nghề và từ những kết quả nghiên cứu tổng quan, cho thấy một cái nhìn bao quát sự chênh lệch về KNTHNN của người dược sĩ tại các nước. Trong đó, kết quả ở nước ta nói lên một thực trạng đáng báo động về KNTHNN của nhần viên y tế.

Nghiên cứu của Seiberth J. M. (2020) với phương pháp quan sát bí mật cho thấy kỹ năng hỏi để thu thập thông tin từ người bệnh nhìn chung là cao nhất so với 4 nghiên cứu khác [4], [7], [10], [2]. Và ngay cả ở Đức, cũng không có thông tin điện tử về người bệnh mà chỉ có một vài nhà thuốc ghi lại các thông tin liên quan về lịch sử pha chế hoặc dị ứng thuốc của khách hàng. Những thông tin quan trọng này lại không được chia sẻ giữa các nhà thuốc hay chuyên gia chăm sóc sức khỏe có thể bỏ sót các trường hợp khách hàng với tình trạng sức khỏe đặc biệt [10].

Về kỹ năng tư vấn - cung cấp thông tin của NVBH, các thông tin về tác dụng phụ của thuốc được chọn mua ít được xem là quan trọng nên ít được tư vấn nhất mặc dù các khuyến cáo và quy định đều đưa ra tiêu chí cung cấp thông tin. Do đó người dược sĩ tư vấn cần khéo léo biết cách nào là an toà̀n và dễ tiếp cận để thông báo cho người bệnh về thông tin tác dụng phụ [10].

Kỹ năng đưa ra lời khuyên để người bệnh đến gặp bác sĩ có tỉ lệ chênh lệch cao giữa nghiên cứu ở Úc và Đức [4], [10]. Nghiên cứu ở Việt Nam sử dụng tình huống mua thuốc kê đớn nhưng không có NVBH nào tư vấn người bệnh đến gặp bác sĩ điều trị. Điều này có thể được giải thích bởi thói quen sử dụng thuốc của người dân và khả năng tiếp cận cơ sở khám chữa bệnh y tế ở Việt Nam còn hạn chế.

Đa số các nghiên cứu đưa vào tổng quan chỉ mới phần nào đánh giá được các kỹ năng của NVBH mà chưa quy ra điểm thực hành xác định cho đối tượng. Chỉ riêng nghiên cứu ở Việt Nam ghi nhận điểm KNTHNN nhưng lại rất thấp chỉ đạt $1,53 / 20$ điểm [2].

Nghiên cứu tổng quan này cung cấp một cái nhìn tổng thể về KNTHNN của dược sĩ cộng đồng từ nhiều quốc gia trên thế giới bao gồm cả các nước phát triển và đang phát triển. Từ đó có thể dễ dàng so sánh các kỹ năng của NVBH nhằm nhận định khiếm khuyết để cải thiện nhân lực y tế của các nước trong tương lai. Nghiên cứu vẫn còn một số hạn chế bao gồm giới hạn về thời gian nghiên cứu, cơ sở dữ liệu và ngồn ngữ nghiên cứu có thể chưa thu thập được toàn diện các nghiên cứu cùng chủ đề. thời gian nghiên cứu ngắn hạn chưa mở rộng tổng quan hệ thống trên nhiều phương pháp nghiên cứu khác để có cái nhìn đa chiều hơn trong việc đánh giá KNTHNN. 


\section{KẾT LUÂN}

Kỹ năng thực hành nghề nghiêp của dược sĩ cộng đồng có mức độ khác biệt ở các quốc gia với mức cao ở quốc gia phát triển và mức thấp ở các quốc gia đang phát triển trong đó có Việt Nam. Những can thiệp hướng đến tập huấn nâng cao và kiểm tra giám sát kỹ năng thực hành nghề nghiệp của dược sĩ cộng đồng cần được quan tâm hơn ở các quốc gia đang phát triển.

\section{TÀl LIÊU THAM KHẢO}

1. Bộ Y tế (2018), "Thông tư số 02/2018/TTT-BYT qưy định về "Thực hành tốt cơ sở bán lẻ thuốc"'.

2. Trân Minh Luẩn, Nguyễn Thanh $\mathbf{V y}$, Nguyễn Thị Thu Thủy (2017), "Đánh giá kỹ năng thực hành nghề nghiêp của người bán lẻ thuốc tai các nhà thuốc đat tiều chuẩn GPP trên địa bàn thành phố Cao Lãnh t tỉnh Đồng Tháp". 492, pp. 2-5.

3. WHO (2018), Tổng quan quốc gia về nhân lực y tế Việt Nam.

4. Collins J. C. et al. (2017), "Management of common ailments requiring referral in the pharmacy: a mystery shopping intervention study", Int J Clin Pharm. 39 (4), pp. 697-703.

5. Eichenberger P. M. et al. (2010), "Classification of drug-related problems with new prescriptions using a modified PCNE classification system", Pharm World Sci. 32 (3), pp. 362-372.

6. Federal.Chamber.of.Pharmacists (2019) Guideline of the Federal Chamber of Pharmacists: Information und Beratung des Patienten bei der Abgabe von Arzneimitteln-Selbstmedikation [Information and counselling of patients during the supply of medicines-self-medication].

7. Hammad E. A. et al. (2018), "A simulated patient study assessing over the counter supply and counseling in Jordan: responding to headache complaints", Int J Clin Pharm. 40 (5), pp. 982-986.

8. Pharmaceutical.Society.of. Australia (2006), Standards for the provision of pharmacy medicines and pharmacist only medicines in community pharmacy.

9. Schumacher P. M. et al. (2019), "Counseling patients on correct drug handling in German community pharmacies: experiences and opinions of pharmaceutical staff", Int J Clin Pharm. 41 (1), pp. 151-158.

10. Seiberth J. M. et al. (2020), "What is the attitude towards and the current practice of information exchange during self-medication counselling in German community pharmacies? An assessment through self-report and non-participant observation", PLoS One. 15 (10), pp. e0240672.

\title{
THỰC TRẬ SÂU RĂNG CỦA SINH VIÊN NĂM THỨ NHẤT TRƯỜ'NG ĐẠI HỌC Y HÀ NộI NĂM HỌC 2020-2021
}

\author{
Hồng Thúy Hạnh¹, Trịnh Minh Báu1, Nguyễn Thị Khánh Huyền',
} Đỗ Sơn Tùng ${ }^{1}$, Đố Hoàng Việt ${ }^{1}$, Phùng Lâm Tới ${ }^{2}$, Hoàng Bảo Duy ${ }^{1}$

\section{TÓM TẮT}

Nghiên cứu mô tả cắt ngang để xác định thực trạng sâu răng được thực hiện trên 770 sinh viên năm thứ nhất trường đải học $Y$ Hà Nôi từ tháng 10 năm 2020 đến tháng 5 năm 2021. Kết quả cho thây: Tỷ lệ sâu răng của sinh viên năm thứ nhất trường đại học Y Hà Nội là $84,55 \%$ trong đó tỷ lệ sâu răng sớm là $62,48 \%$. Chỉ số DMFT là $5,09(D=4,72 ; M=0,04$; $\mathrm{F}=0,33)$. Tỷ lệ sâu răng và chỉ số DMFT đang ở mức cao theo phân loai của WHO.

Ti̛ khóa: sẩu răng, DMFT, sâu răng sớm, sinh viên y, Đại học Y Hà Nội.

\section{SUMMARY \\ DENTAL CARIES STATUS OF FIRST-YEAR STUDENTS HANOI MEDICAL UNIVERSITY}

\footnotetext{
1 Viện Đào tạo Răng Hàm Mặt, trường Đại học Y Hà Nội ${ }^{2}$ Viện Chiến lược và Chính sách Y tế - Bộ Y tế Chịu trách nhiệm chính: Hoàng Bảo Duy Email: drhoangbaoduy@gmail.com Ngày nhận bài: 16.9.2021

Ngày phản biện khoa học: 12.11.2021

Ngày duyệt bài: 22.11.2021
}

IN SCHOOL YEAR 2020 - 2021

A descriptive cross-section in order to determine dental caries status is conducted on 770 first-year students at $\mathrm{Ha}$ Noi Medical University. The results showed that: The total rate of dental caries was $84,55 \%$, of which early dental caries rate was $62,48 \%$. DMFT index: $5,09 \quad(D=4,72 ; M=0,04$; $\mathrm{F}=0,03)$. The rate of dental caries and DMFT index were high according to WHO classification.

Keyword: dental caries, DMFT, early dental caries, medical student, Ha Noi Medical University.

\section{I. ĐĂT VẤN ĐỀ}

Vào những năm 75 của thế kỉ $X X$, tổ chức $y$ tế thế giới (WHO) đã xếp 3 trong số hơn 10 bệnh phổ biến là tai họa của loài người: bệnh tim mạch, bệnh ung thư và bênh sâu răng [1]. Cho đển hiện nay sâu răng vẫn đang là một gánh nặng trong chăm sóc sức khỏe răng miệng toàn cầu. Tỷ lệ sâu răng ở lứa tuổi thanh thiếu niên còn khá cao: cuộc điều tra sức khỏe răng miênng toàn quốc lần 2 năm 2001 của Trần Văn Trường cho thây tỷ lệ sâu răng lứa tuổi 18 là 75,2\%[2], nghiên cứu của Drachev và cộng sự năm 2017 